\title{
Enhancement transient stability of power system using UPFC with M-PSO
}

\author{
Rashid H. AL-Rubayi, Luay G. Ibrahim
}

Department of Electrical Engineering, University of Technology, Iraq

\begin{tabular}{l}
\hline \hline Article Info \\
\hline Article historys: \\
Received Mar 20, 2019 \\
Revised Jul 17, 2019 \\
Accepted Aug 4, 2019 \\
\hline
\end{tabular}

\section{Keywords:}

FACTS

MMPS

PI-C-PSO

PI-C-M-PSO

UPFC

Transient stability

\begin{abstract}
During the last years, the demand for electric power has increased dramatically, while the expansion of energy production and transmission has been brutally expanded due to resource and environmental constraints. So, many transmission lines were loaded deeply; thus, the stability of power system became a limiting factor for the transmission of electric power. Therefore, maintaining safe and stable operation of electrical grids is an important and challenging issue. The FACTs devices that provide opportunities to control the power and damping oscillations are used. Therefore, this paper sheds light on the modified particle swarm optimization (M-PSO) algorithm is used such in the paper to discover the design optimal the Proportional Integral controller (PI-C) parameters that improve the stability the Multi-Machine Power System (MMPS) with Unified Power Flow Controller (UPFC) by employing the MATLAB environment. Performance, the power system under event of fault, is investigating by utilizes the proposed two strategies to simulate the operational characteristics of power system by the UPFC using: first, the conventional (PI-C) based on PSO (PI-C-PSO) method; secondly, (PI-C) based on modified PSO (PI-C-MPSO) method. The simulation results show the behavior of power system with and without UPFC, that the proposed (PI-C-M-PSO) technicality has enhanced response the system compared for other techniques, that since it gives undershoot and over-shoot previously existence minimized in the transitions, it has a ripple lower. The obtained results show that the transient stability of the simulation model has improved significantly with this technique.
\end{abstract}

Copyright $\odot 2020$ Institute of Advanced Engineering and Science. All rights reserved.

\section{Corresponding Author:}

Luay G. Ibrahim,

Department of Electrical Engineering,

University of Technology, Baghdad, Iraq.

Email: Luay_g@ yahoo.com

\section{INTRODUCTION}

Currently, power transmission networks have become narrower due to the increased demand for power. A result of many stability problems such as overloading some transmission lines after a disturbance.Complex and interconnected power grids cause some technical problems as a system stability issue. Therefore, the problem of transitory stability after the main defect is a special transmission-limiting factor [1]. The stability of the power system for large systems is an important and fundamental problem for the safe operation of the system. Moreover, the stability of electrical systems around the world, even in advanced and protected systems, is vulnerable to system instability as a result of sudden changes on the network [1, 2]. The transient stability mentions to the capacity of the power system to preserve synchronization when exposed to acute transient disturbances such as unexpected change of load and faults [3]. Comprise system response resulting from large fluctuations in generator speed and rotor angle. Transient stability of the intricate power system can be enhanced using FACTs devices [4]. 
The FACTs controllers are able to control the network condition highly quick. This lets the present network to obtain used efficiently and thus evade the necessity for making newlines [5]. The optimal tuning and modelling numerous of FACTs devices for dynamic stability improvement for MMPS studied in [6]. Presently, FACTS devices are individually controlled. In any case, the innovative methods and techniques have been able to control the power systems, enhancement the reliability and capacity of the electric power transmission, and also maintain the stability of the system. The controllers are increasing the power transmission capacity available to provide more convenient and quiet electricity coefficients to make the system more robust and robust [7].

The UPFC is the most widely deployed device in FACTs that can provide effective control of power system parameters such by way of transmission voltage, line impendence, and phase angle. Moreover, UPFC can provide either positive or negative power injections positive or interactive. Therefore, it can enhance the operation of the system because it allows for extra efficient control of power flow, super-control system, and stability [8]. The PI-controller becomes been used in recent years to improve both temporary and fixed performance, as well as to reject disturbances caused by startup events [9-11]. This work proposes a new MPSO; the modification was developed by new inertia weight (Wnew) and modified new acceleration factor (Cnew1, Cnew2) based on linearly decreasing. The focus has been on improving the performance of the UPFC connected to the grid to overcome the disturbances that occur in the network by controlling the PI using two scenarios; first, (PI-C-PSO); secondly, (PI-C-M-PSO). Finally, the proposed strategies show is effective in stabilization, over-shoot, and under-shoot already being minimized in the transitions.

\section{RESEARCH METHOD}

\subsection{Control of UPFC}

UPFC is the commonly versatile member from FACTs devices, by using power electronics ability to control the flow of power on the power networks. The UPFC implements a mixture of a series controller (SSSC) and shunt controller (STATCOM); these controllers interconnected over the shared DC bus as presented in Figure 1 [12].

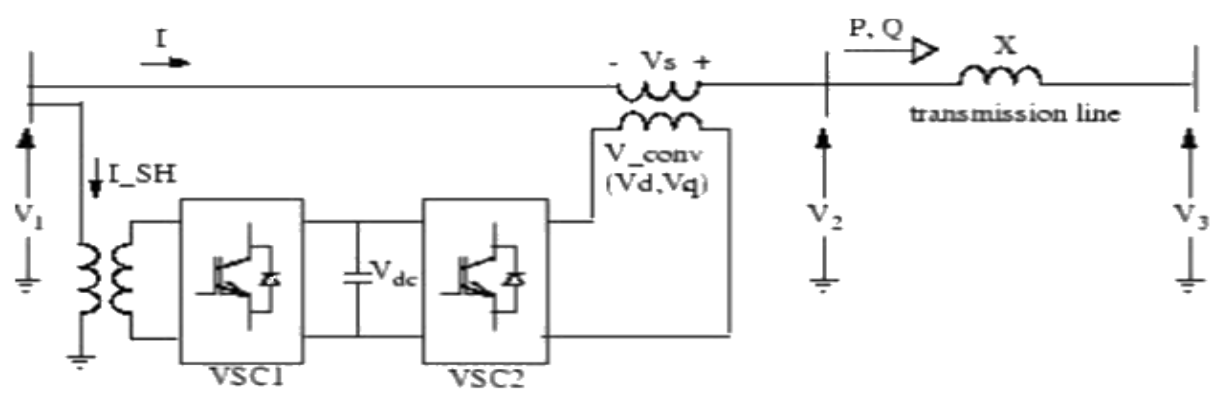

Figure 1. The basic scheme of UPFC

Both of shunt and series converters employ Voltage Sourced Converter (VSC), which connected to the secondary of the coupled transformer. VSC works to force the commutated power electronic elements (GTO, IGBT or IGCT) to create a voltage from the D.C voltage source. The shared capacitor, which connected to D.C side of the VSC, operates as D.C voltage source.

\subsubsection{Shunt converter controls}

The shunt converter controls the magnitude of the voltage at the sending end bus. This converter has two commitments: generating or absorbing active power and to supplying or absorbing reactive power at the dc terminals as requested by the series converter. Controlling the dc voltage accomplishes the balance of real power between the shunt and series converter as an overabundance or of shortage, the real power will stand faced by increasing or decreasing the dc voltage, respectively.

Based on changing the angle and magnitude of the produced voltage of the shunt converter, the reactive and active power flow in the shunt converter is controlled [13, 14]. The dynamic blocks of the shunt controller appear in Figure 2. 


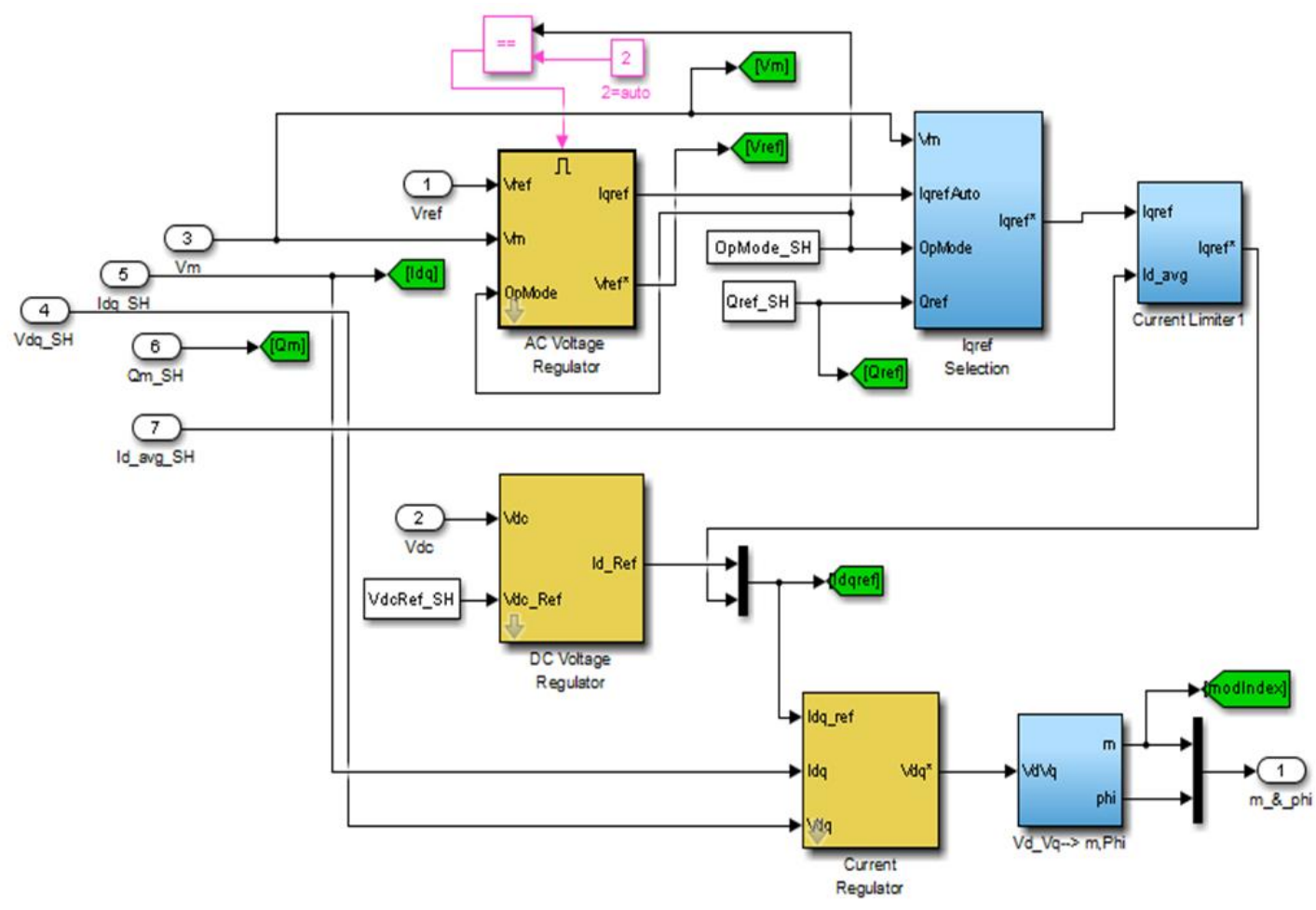

Figure 2. Dynamic blocks of shunt controller for UPFC

\subsubsection{Series converter controls}

For the series converter control, two different control approaches are implementing. The first one is to control the real and the reactive power flow in the transmission line, other control schemes for controllingthe flow of the real power in the transmission line and voltage amplitude at receiving end bus. According tothe theory for UPFC, the serial converter is the primary of the UPFC; two PI controllers separately are using to control real and reactive power. The flow of real power influenced by changes phase angles. On theother sense, the flow of reactive power directly related to the voltage amplitude. The series converter, as presented in Figure 3.

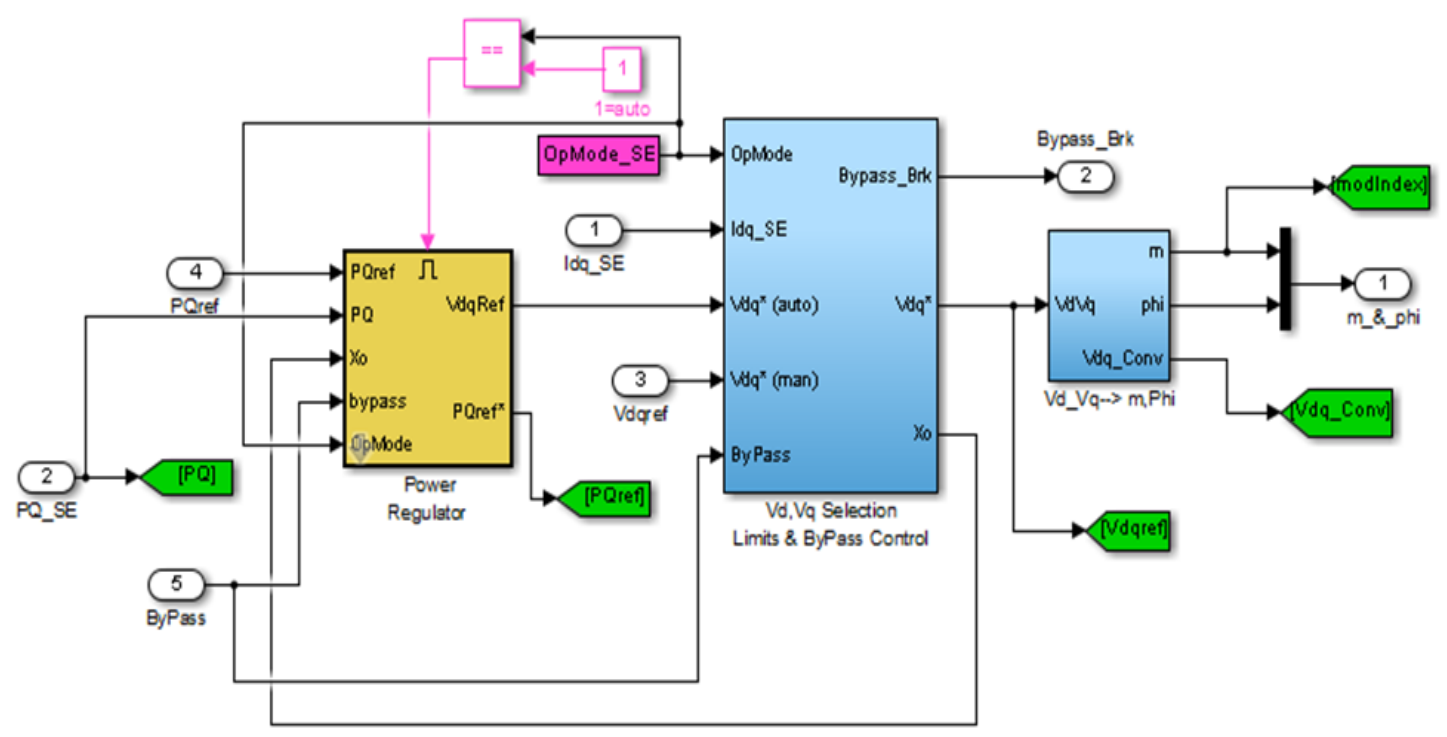

Figure 3. Dynamic Blocks of the series controller for UPFC 


\subsection{Particle Swarm Optimization (PSO)}

The PSO is a one of the improved algorithms optimization method sophisticated in 1995 by Eberhart and Kennedy based on the societal demeanour of group of birds, school of fish, and the swarm of bees while searching for food, the even sometimes-social behavior of human. The method of the PSO algorithm in determining optimal values follows the action of the animal community in which there is no leader. A flock of animals that have fined food by random, from one place to another; follow one of the group members to have the nearest position with the food source (optimal solution) $[15,16]$.

The PSO algorithm consists of a particle swarm, where particles exemplify a likely solution (a better case). The particle will move in the multidimensional search area to obtain the best position in that area. If the brand-new location of the particle is away from the best in the global and the best is local, the speed will accelerate the shift to great value. The particles stay updated according to the following equation:

$$
\begin{aligned}
& v_{i, j}^{m+1}=w v_{i, j}^{m}+c_{1} \operatorname{rand}_{1} *\left(P_{\text {best } i, j}-x_{i, j}^{m}\right)+c_{2} \operatorname{rand}_{2} *\left(g_{\text {best } i, j}-x_{i, j}^{m}\right) \\
& x_{i, j}^{m+1}=x_{i, j}^{m}+v_{i, j}^{m+1}
\end{aligned}
$$

Where $v_{i, j}^{m}$ : Current velocity of particle $i$ at iteration $k, v_{i, j}^{m+1}$ : Modified velocity of particle $i, w$ : Inertial weight factor, $c_{1}, c_{2}$ : known as acceleration constants, $\operatorname{rand}_{1} \& \operatorname{rand}_{2}$ : random numbers between 0 and $1, x_{i, j}^{m}$ : Current position of particle $i$ at iteration $m, x_{i, j}^{m+1}$ : Modified position of the particle $i, P_{b e s t} i, j$ : The best position of a specific particle, $g_{\text {best } i, j}$ : The best particle of the group.

\subsection{PI Controller with modified PSO algorithm}

UPFC has an application in the system to improve transient stability by choosing optimum PI-C parameters of UPFC by utilizing the PI-C-M-PSO method. In the suggested PI-C-M-PSO method, each particle contains two $K p, K i$ members. In other words, the area of search for a problem has two dimensions;also each particle in the group should aviation in a two-dimensional area. Figure 4 shows the flowchart of the PI-C method utilizing the M-PSO algorithm to adjust the PI-C and to collect optimum parameter values.

The Important step in the PSO application, Selection the fitness function utilized to assess the fitness of every particle. In the PI-C, here considered as performance criteria common are Integrated Absolute Error (IAE), which is the integrated of time weight square error (ITSE) and integrated of square error (ISE) which can be assessed analytically under the frequency domain. There are advantages and disadvantages of the three performance indicators. As the example, the problem of the ISE and IAE indicators means that its reduction can lead to response but with a relatively simple over-shoot in a long time of stability. Although the ITSE performance indicator reduces ISE imperfections, calculating this indicator is complex and timeconsuming [17].

The PI-C M-PSO performed using the same diagram as shown in Figure 4 and all the predefined equations for PI-PSO implementation, and the modification hither is the most efficient factors into optimum convergence with Optimal Global namely inertial weight and acceleration factors. In this respect, the adjusted inertial weight has the same primary and ultimate values as in the linear function but a sharp reduction rate. A small value of $\mathrm{W}$ encourages domestic utilization while a value greater than $\mathrm{W}$ supports global utilization, the result will improved convergence rate and miniature time spent to complete global search and to obtain an appropriate global solution, The basic algorithm for PSO is modification that did develop by (Wnew) and the new accelerator factor (Cnew1, Cnew2) based On the linear decrease. The values of $W$ evaluated and (Cnew1, Cnew2) calculated as follows:

$$
\begin{aligned}
& W_{\text {new }}=w_{\text {max }}-\frac{w_{\text {max }}-w_{\text {min }}}{\text { Maxite }} * \text { ite } \\
& C_{\text {new } 1}=C_{\text {max } 1}-\frac{C_{\text {max } 1}-C_{\text {min } 1}}{\text { Maxite }} * \text { ite } \\
& C_{\text {new } 2}=C_{\text {max } 2}-\frac{C_{\text {max } 2}-C_{\text {min } 2}}{\text { Maxite }} * \text { ite }
\end{aligned}
$$


Where: $w_{\max }$ : Maximum weight, $w_{\min }$ : Minimum weight, Maxite: Maximum iteration number, ite: Current iteration number, $C_{\max 1}$ : Maximum acceleration factor, $C_{\min 1}$ : Minimum acceleration factor, $C_{\max 2}$ : Maximum acceleration factor, $C_{\min 2}$ : Minimum acceleration factor.

The M-PSO method in this work depends on (ITSE) performance index. The ITSE is implemented utilizing an integrator, clock, product, mathematical function (to represent the absolute mathematical operation) and to workspace blocks, connect these blocks to the error signal to the PI-C for power regulator in the series converter and A.C voltage regulator in shunt converter of UPFC, for shown in Figures 5 and 6.

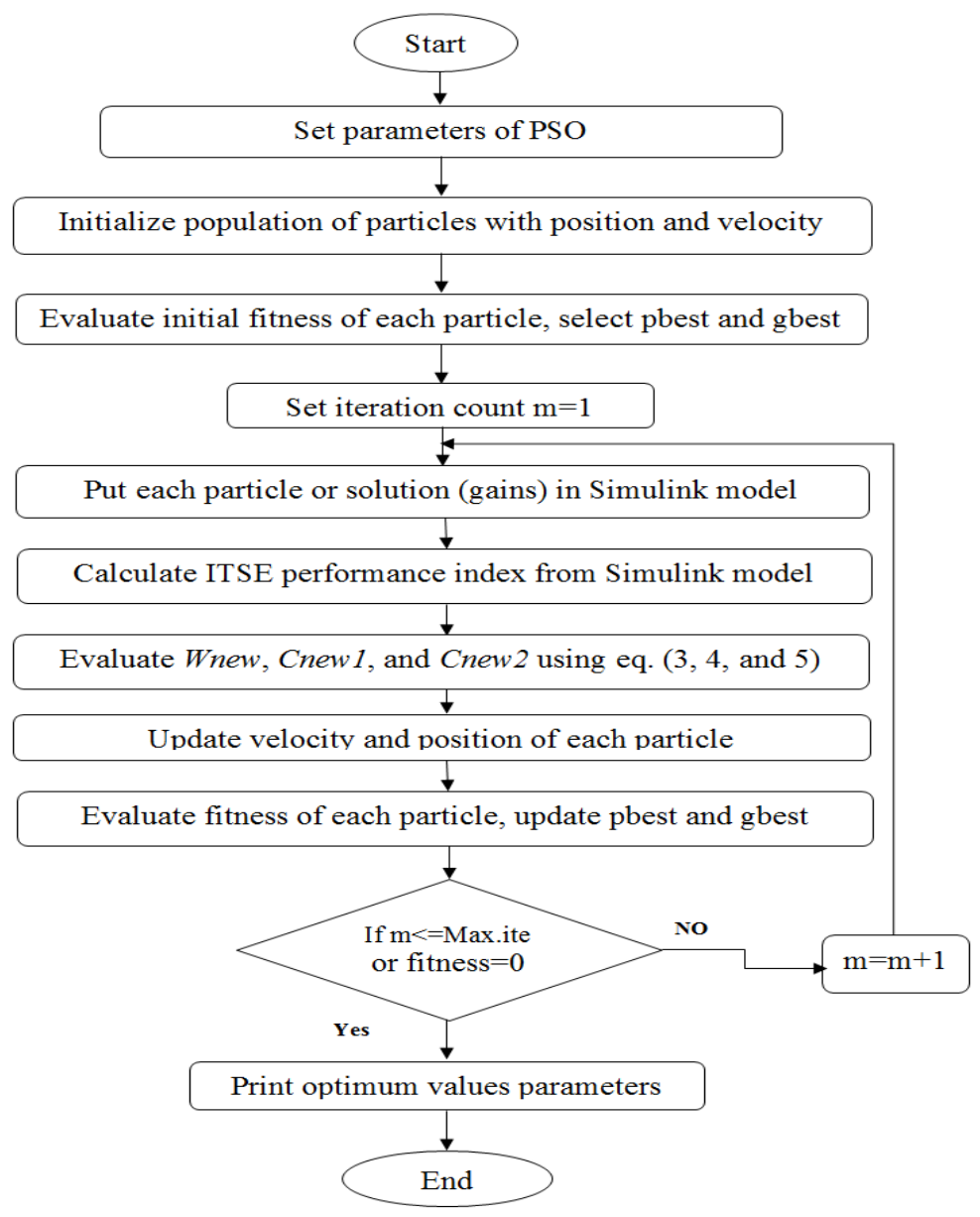

Figure 4. Flowchart of PI-C and M-PSO algorithm

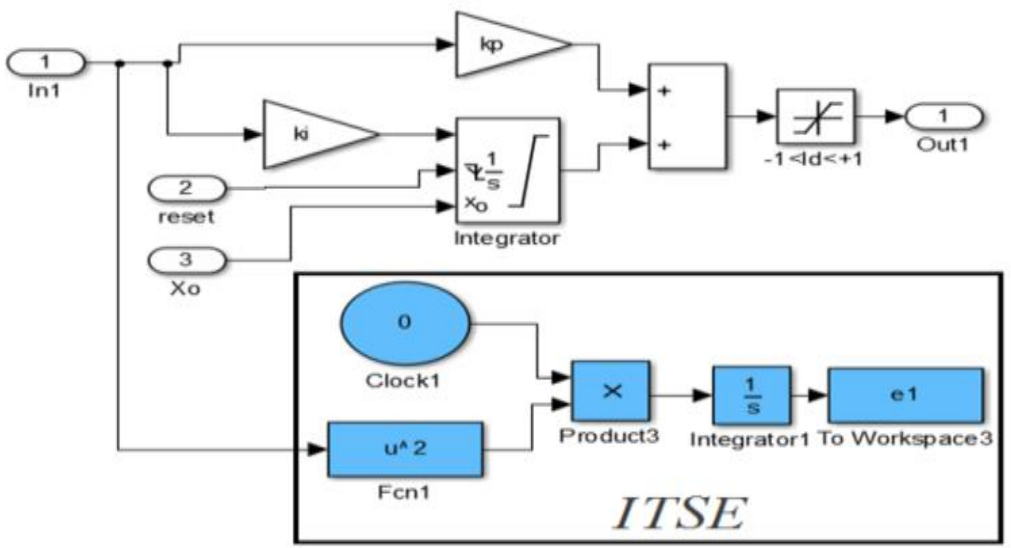

Figure 5. PI controller of UPFC (series converter) 


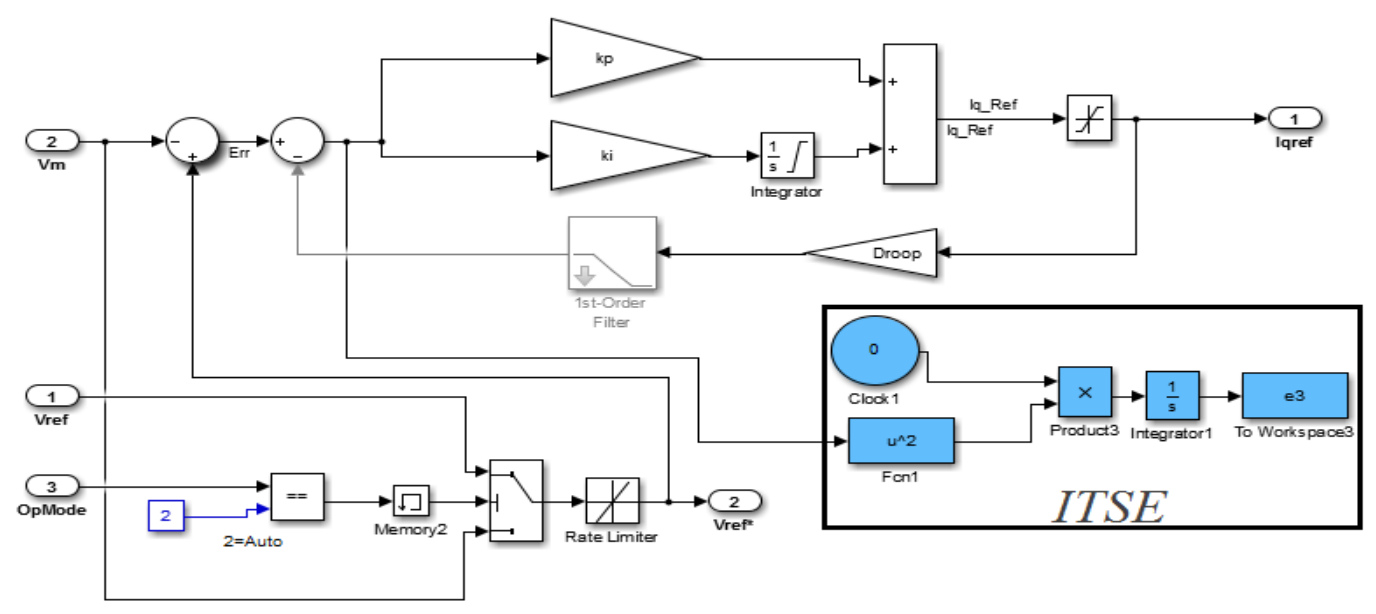

Figure 6. PI controller of UPFC (shunt converter)

\section{RESULTS AND DISCUSSION}

The complete system of the IEEE 9 bus system designed with all required components using the MATLAB/Simulink blocks shown in Figure 7 for analysis and system data given in [18]. The UPFC device is located in transmission line 4 between buses 5 to 7 in the IEEE 9-bus, as shown in Figure 7 [19, 20]. Three phases to ground fault occur near bus 7; the faulted line 2 will be removed to clear the fault t_c $=1.081$ sec.

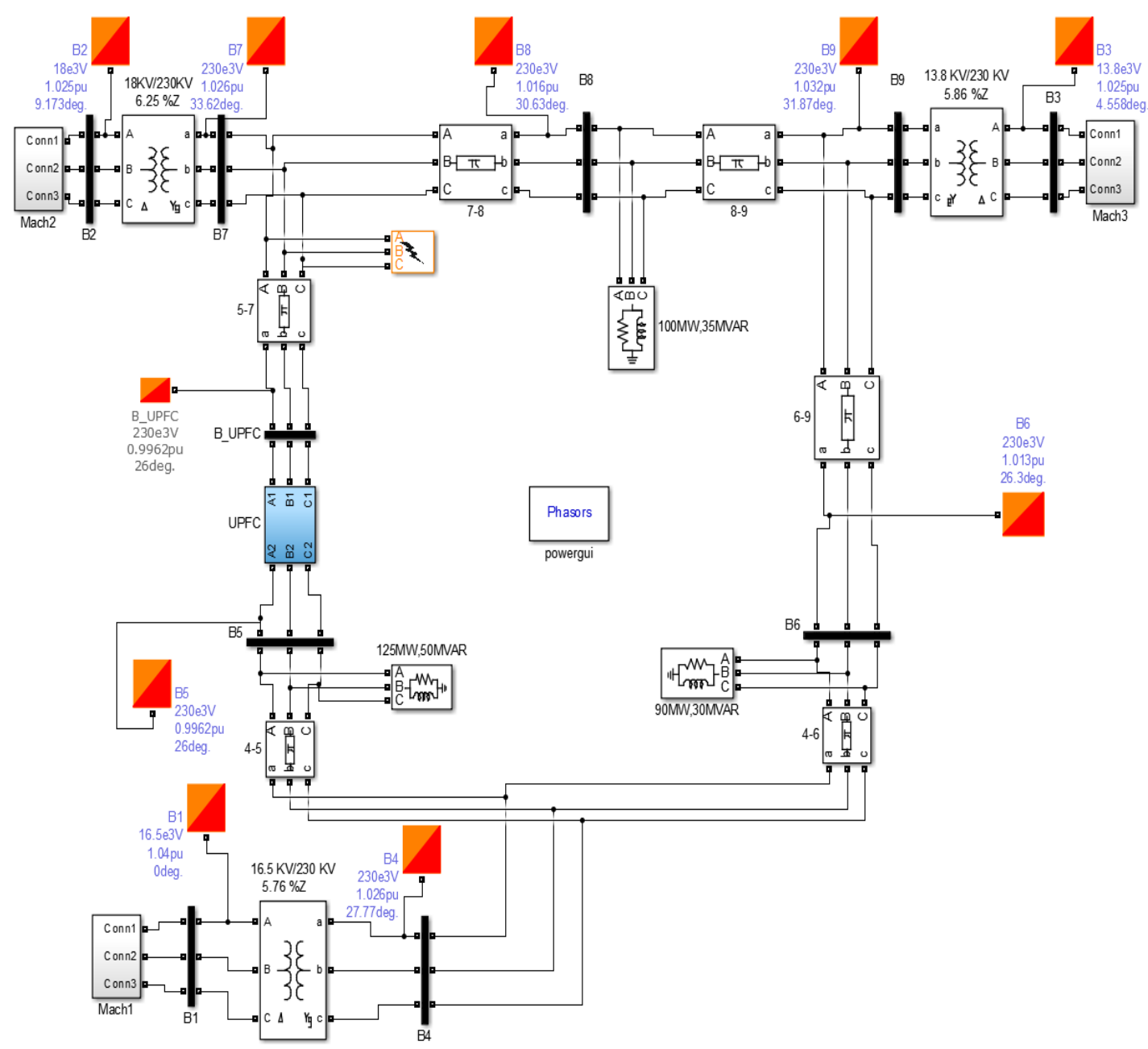

Figure 7. Simulink model of the IEEE 9-bus 
After the select optimal parameters in PSO of the UPFC, the M-PSO algorithm enables optimizing the values of controller gains make the controller robustly and have good results. The parameters of PI controllers obtained by M-PSO technique illustrated in Table 1. Figure 8 and Figure 9 show the oscillations of rotor angle for Gen.-2 and Gen.-3 with references Gen.-1 for 3- phases to a ground fault occurring near bus 7 . The fault occurs during $0.081 \mathrm{sec}$. These figures are displayed the rotor angle without and with the existence of UPFC in the power system. From this, it is clear that UPFC with the suggested controller has verified that the PI-C-M-PSO response offers better consequences than the PI-C-PSO. Furthermore the overshoot and undershoot already being minimized in the transitions with lower ripple.

The comparison between different controllers for the rotor angle oscillations of Gen.-2 and Gen.-3 with references Gen.-1 for 3-phases to ground fault occurs near bus 7 with the presence of UPFC illustrated in Table 2 and Table 3.

Table 1. PI-controller parameters for PI-C-PSO and PI-C-M-PSO

\begin{tabular}{ccccc}
\hline & \multicolumn{2}{c}{ Power regulator gains(series converter) } & \multicolumn{2}{c}{ Voltage regulator gains(shunt converter) } \\
\hline PI Parameters & Kp1 & Ki1 & Kp2 & Ki2 \\
PI-C-PSO & 0.012 & 1.8 & 4 & 1019 \\
PI-C- M-PSO & $6.97803 \mathrm{e}^{-5}$ & 1.60984 & 5.72622 & 994.47799 \\
\hline
\end{tabular}

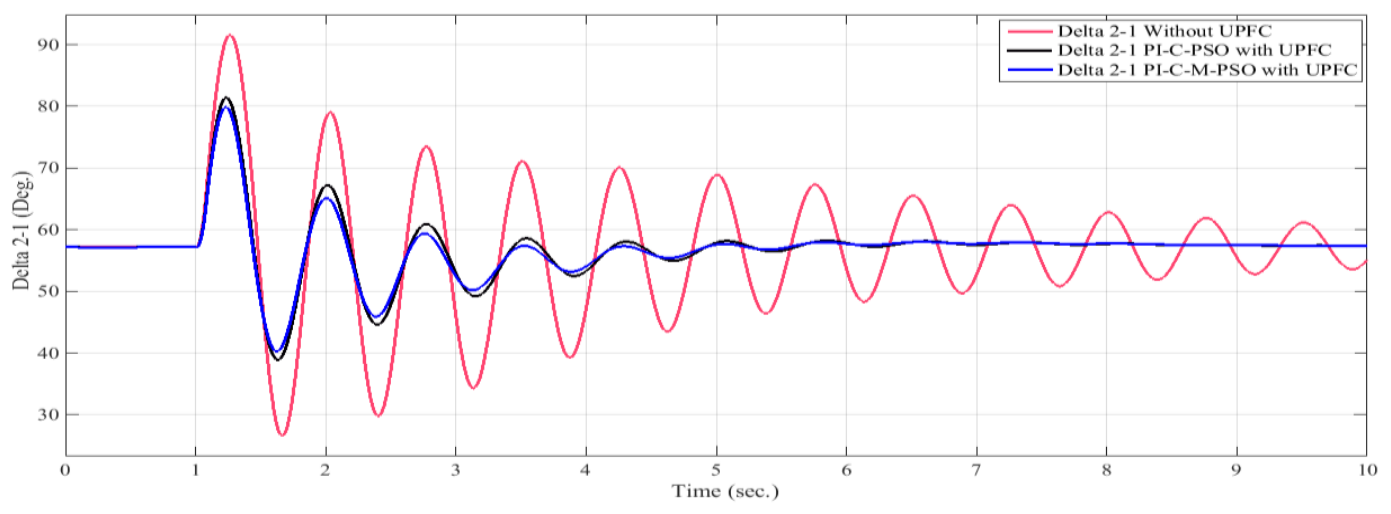

Figure 8. Rotor angle oscillations of gen.-2 with references gen.-1 with and without UPFC

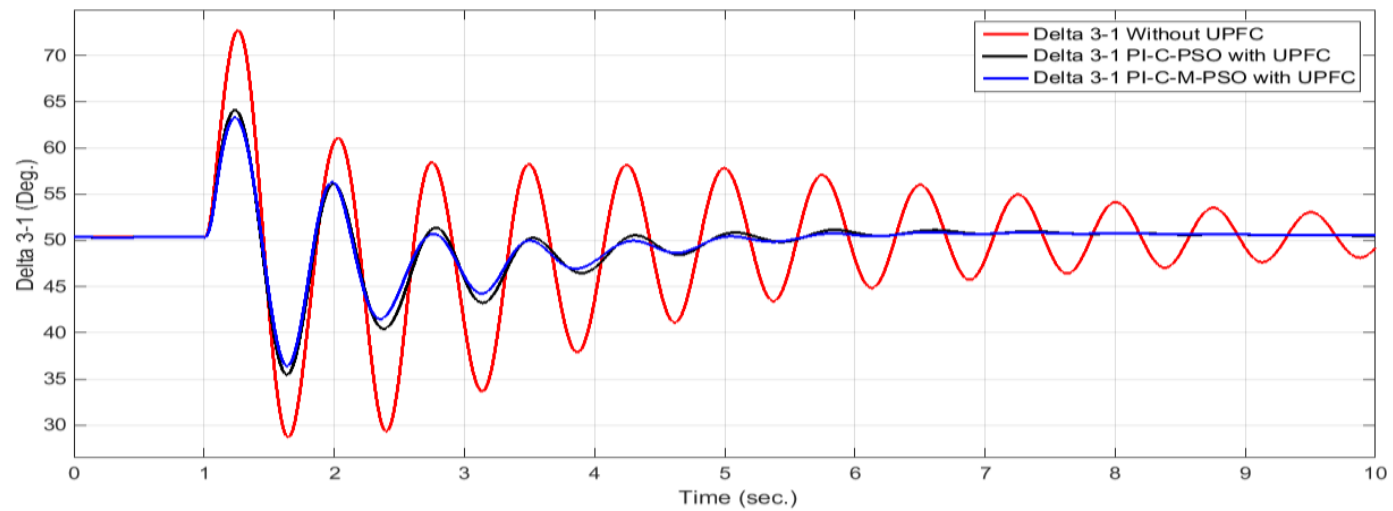

Figure 9. Rotor angle oscillations of gen.-3 with references gen.-1 with and without UPFC

Table 2. A comparison between different controllers for rotor angle of gen.-2 with references gen.-1

\begin{tabular}{cccc}
\hline Strategy type & Overshoot (deg.) & Undershoot (deg.) & Settling time (s) \\
\hline Without UPFC & 91.58 & 26.53 & 26.25 \\
PI-C-PSO with UPFC & 81.40 & 38.90 & 9.267 \\
PI-C-M-PSO with UPFC & 79.89 & 40.26 & 7.677
\end{tabular}


Table 3. A comparison between different controllers for rotor angle of gen.-3 with references gen.-1

\begin{tabular}{cccc}
\hline Strategy type & Overshoot (deg.) & Undershoot (deg.) & Settling time (s) \\
\hline Without UPFC & 72.74 & 28.69 & 24.87 \\
PI-C-PSO with UPFC & 64.10 & 35.48 & 9.183 \\
PI-C-M-PSO with UPFC & 63.30 & 36.43 & 7.494 \\
\hline
\end{tabular}

Figure 10 and Figure 11 show rotor speed deviation of Gen.-2 and Gen.-3 with references Gen.-1 for 3-phases to a ground fault occurring near bus 7. These plots displayed the rotor speed deviation without and with the existence of UPFC in the power system. UPFC with the suggested controller verified that the PIC-M-PSO response provides better effects than the power system using PI-C-PSO. Also, over-shoots and undershoot are minimized in transitions; and it has less ripple.

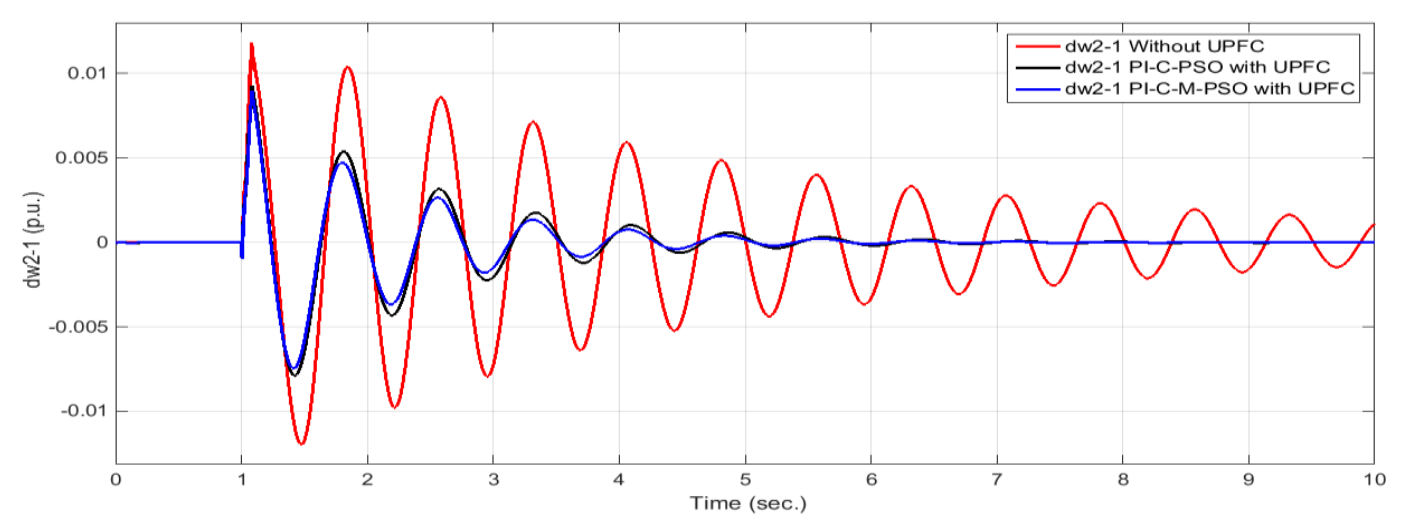

Figure 10. Rotor speed deviation of gen.-2 with references gen.-1 with and without UPFC

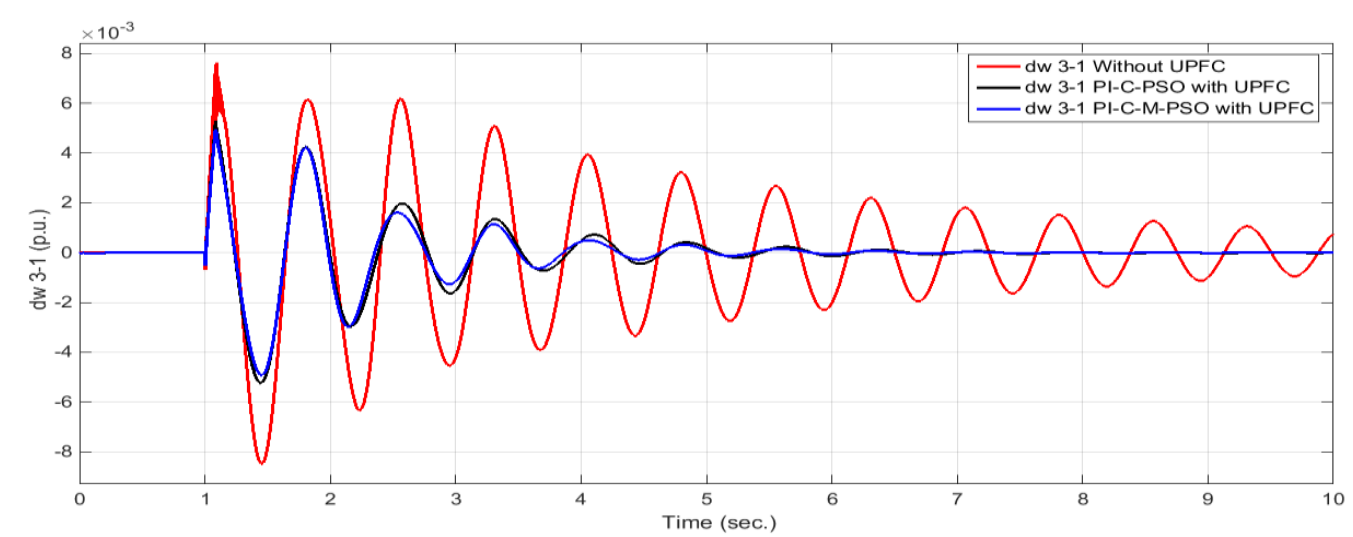

Figure 11. Rotor speed deviation of gen.-3 with references gen.-1 with and without UPFC

The comparison between different controllers for rotor speed deviation oscillations of Gen.-2 and Gen.-3 with references Gen.-1 for 3-phases to ground fault occurs near bus 7 with the presence of UPFC illustrated in Table 4 and Table 5.

Table 4. A comparison between different controllers for rotor speed of gen.-2 with references gen.-1

\begin{tabular}{cccc}
\hline Strategy type & Overshoot (p.u) & Undershoot (p.u) & Settling time (s) \\
\hline Without UPFC & 0.0118 & -0.01195 & 26.35 \\
PI-C-PSO with UPFC & $9.244 * 10^{-3}$ & $-7.888 * 10^{-3}$ & 9.350 \\
PI-C-M-PSO with UPFC & $8.897 * 10^{-3}$ & $-7.465 * 10^{-3}$ & 7.883 \\
\hline
\end{tabular}


Table 5. A comparison between different controllers for rotor speed of gen.-3 with references gen.-1

\begin{tabular}{cccc}
\hline Strategy type & Overshoot (p.u) & Undershoot (p.u) & Settling time (s) \\
\hline Without UPFC & $7.616^{*} 10^{-3}$ & $-8.493 * 10^{-3}$ & 27.45 \\
PI-C-PSO with UPFC & $5.302 * 10^{-3}$ & $-5.234^{*} 10^{-3}$ & 9.217 \\
PI-C-M-PSO with UPFC & $4.957 * 10^{-3}$ & $-4.925 * 10^{-3}$ & 7.383 \\
\hline
\end{tabular}

\section{CONCLUSION}

This paper provides an M-PSO algorithm to improve PI-C parameters to enhance the transient stability of the power system. The power system studied by MMPS expressed with UPFC by PI-C. The research paper problem enclosed as improvement problem in about of PI-C parameters, and the M-PSO algorithm utilized to determine optimum parameter values. The efficiency of the proposed technique inspected in the case of fault; the obtained results are compared to PI-C-PSO \& PI-C-M-PSO. The simulation results showed that M-PSO is capable of generating optimal transitional response characteristics. Hence, the suggested scenarios for enhancing transient stability commingle the benefits of PI-C with the M-PSO and the installation UPFC device to manipulate the fault.

\section{REFERENCES}

[1] M. I. Azim, M. A. Wahed, and M. A. H. Chowdhury, "Power flow and transient stability improvement by static synchronous series compensator," Indonesian Journal of Electrical Engineering and Computer Science, vol. 15, pp. 71-77, 2015.

[2] L. Giang, N. Thuy, and T. Ngoat, "Assessment Study of STATCOM's Effectiveness in Improving Transient Stability for Power System," Telkomnika (Telecommunication, Computing, Electronics, and Control), vol. 11, pp. 6095-6104, 2013.

[3] N. G. Hingorani, L. Gyugyi, and M. El-Hawary, Understanding FACTS: concepts and technology of flexible AC transmission systems vol. 1: IEEE Press, New York, 2000.

[4] V. Mahajan, "Power system stability improvement with flexible AC transmission system (FACTS) controller," in 2008 Joint International Conf. on Power System Technology and IEEE Power India Conf., 2008, pp. 1-7.

[5] M. Mohammadinia and M. Borzouie, "Optimal placement of FACTS devices to improve transient stability of multimachine power system," in 2008 IEEE/PES Transmission and Distribution Conference and Exposition.

[6] M. Haque, "Use of series and shunt FACTS devices to improve first swing stability limit," in 2005 International Power Engineering Conference, 2005, pp. 1-365.

[7] Y. Kumari, A. Gupta, S. P. Bihari, R. Chaubey, and B. Sehgal, "Performance and Analysis of Reactive Power Compensation by Unified Power Flow Controller," Indonesian Journal of Electrical Engineering and Informatics (IJEEI), vol. 3, pp. 141-149, 2015.

[8] M. K. G. Damor, M. V. Agrawal, D. D. M. Patel, and M. H. G. Patel, "Improving Power System Transient Stability by using Facts Devices," International Journal of Engineering Research \& Technology (IJERT), 2014.

[9] S. S. Khorramabadi and A. Bakhshai, "Critic-based self-tuning PI structure for active and reactive power control of VSCs in microgrid systems," IEEE Transactions on smart grid, vol. 6, pp. 92-103, 2015.

[10] A. V. Sant, K. Rajagopal, and N. K. Sheth, "Permanent magnet synchronous motor drive using hybrid PI speed controller with inherent and noninherent switching functions," IEEE Transactions on Magnetics, vol. 47, pp. 40884091, 2011.

[11] A. Rodriguez-Martinez, R. Garduno-Ramirez, and L. G. Vela-Valdes, "PI fuzzy gain-scheduling speed control at startup of a gas-turbine power plant," IEEE Transactions on energy conversion, vol. 26, pp. 310-317, 2011.

[12] J. Guo, M. L. Crow, and J. Sarangapani, "An improved UPFC control for oscillation damping," IEEE transactions on power systems, vol. 24, pp. 288-296, 2009.

[13] K. Padiyar and A. Kulkarni, "Control design and simulation of unified power flow controller," IEEE Transactions on Power Delivery, vol. 13, pp. 1348-1354, 1998.

[14] C. Schauder, L. Gyugyi, M. Lund, D. Hamai, T. Rietman, D. Torgerson, et al., "Operation of the unified power flow controller (UPFC) under practical constraints," IEEE transactions on power delivery, vol. 13, pp. 630-639, 1998.

[15] D. P. Rini, S. M. Shamsuddin, and S. S. Yuhaniz, "Particle swarm optimization: technique, system, and challenges," International Journal of computer applications, vol. 14, pp. 19-26, 2011.

[16] S. Malik, P. Dutta, S. Chakrabarti, and A. Barman, "Parameter estimation of a PID controller using particle swarm optimization Algorithm," International Journal of Advanced Research in Computer and Communication Engineering, vol. 3, pp. 5827-5830, 2014.

[17] Z.-L. Gaing, "A particle swarm optimization approach for optimum design of PID controller in AVR system," IEEE transactions on energy conversion, vol. 19, pp. 384-391, 2004.

[18] R. D. Zimmerman and C. E. Murillo-Sánchez, "Matpower 6.0 b2 User’s Manual."

[19] Luay G. Ibrahim and Rashid H. AL-Rubayi,"Optimal Placement of FACTs Devices Using Hybrid Line Stability Index," Journal of Engineering and Applied Sciences, 14(8):2739-2744, 2019.

[20] R. H. Al-Rubayi and W. K. Al-Jubori, "An approach of voltage stability analysis for IEEE 9 bus system with UPFC," Advances in Natural and Applied Sciences, vol. 10, pp. 71-82, 2016. 